\title{
Clarifications and Proposals for Improvement in Romanian Accounting Regulations on Profit Distribution / Cover Loss and Presentation of Information Appropriate
}

\author{
Aristița Rotilă, University "Vasile Alecsandri” of Bacău, România
}

\begin{abstract}
Starting from the analysis of accounting regulations in compliance with European directives applicable to the different categories of entities, as well as from the findings of a study we carried out concerning the financial statements of certain economic agents, in this paper we intend to signal some aspects which, in our opinion, require clarifications, and to launch some proposals leading to the improvement of Romanian accounting regulations, even though these will still be applied over a period of time.
\end{abstract}

\section{Key-words}

net profit, loss, profit distribution, loss covering, employees’ profit sharing

Cod JEL: M41

By means of the study we carried out we observed a series of inconsistencies, ambiguities or contradictions in the accounting regulations applicable to the different types of entities, such as, among others, aspects concerning profit distribution/ loss covering and the presentation of corresponding information in the financial statements of economic agents. Therefore, in our view, we should clarify, among other things, some aspects concerning: the moment of registration in accounting of net profit distribution; the registration of employees' profit sharing, and the presentation of corresponding information; the presentation of the proposal for loss covering.

\section{Concerning the moment of registration of profit distribution in accounting: in financial year $\mathbf{N}$ or $\mathbf{N}+1$ ?}

Both in Accounting Law no. 82/1991, republished in 2008 (art. 19, par. 3), and in accounting regulations applicable to economic agents approved by OMPF no. 3055/2009 (item 248, par. 4), it is stipulated that "the distribution of profit is registered in accounting on destinations after the approval of the annual financial statements". Similarly, Accounting Regulations approved by OMPF no. 3055/2009 (item 248, par. 5) stipulated that, for sums representing legal reserve constituted from the profit of the current financial year on the basis of legal regulations, the registration of profit distribution in accounting is carried out in the current financial year (therefore, not in the next one, after its approval in the General Assembly). For a start, we observe that, by this stipulation, the Regulations come against the Accounting Law, which is very clear and leaves no room for exceptions.

On the other hand, should we thus understand that, for such destinations of the profit, the approval of the General Assembly is no longer needed? The answer cannot be a positive one

1 OMPF no. 3055/ 2009 for the approval of accounting regulations in compliance with European directives, published in Official Monitor no. 766/2009. 
if we take into consideration that, in the exemplifying model of Note 3 Profit distribution, the legal reserve (one based on legal regulations) appears as one of the destinations where the profit is due for distribution (distributable net profit) and so, the General Assembly's approval is also necessary for this destination.

We might think that, as long as it is a reserve which must necessarily be constituted by any commercial company, the approval of the General Assembly would not be necessary. But for what value is its formation compulsory since the law on the basis of which it is constituted ${ }^{2}$ establishes some minimal limits, such as: "a least 5\% from the company's profit" until it reaches "a minimum of a fifth of the share capital"?

The registration of profit distribution for the legal reserve in the financial statements of the current financial year has, in our opinion, no justification except for satisfying fiscal necessities (so that the entity could be able to benefit from this fiscal deduction).

It is well-known the fact that the legal reserve represents, to a certain extent, a fiscal deduction: "the legal reserve is limited to a $5 \%$ deductible quota, until it reaches a fifth of the share capital subscribed and paid-in (...)"3. Therefore, the above-mentioned percentages, minimal limits according to the Commercial Companies' Law, represent maximal limits from a fiscal point of view. It is expected that, from fiscal reasons, at least until the legal reserve reaches that $20 \%$ of the share capital, the entities should not distribute profit for setting up the legal reserve over the limit of fiscal deductibility ( $5 \%$ ). Once the limit of $20 \%$ is reached, it is left at the company's choice to make up legal reserves of greater dimensions, without benefiting from fiscal deductibility. At the same time, if the legal reserve was used for covering losses, the subsequent reconstitution of the reserve is no longer deductible at the calculation of chargeable profit. So, the fiscal reason would not be available either for the argument supporting the registration of this distribution before the General Assembly.

As a consequence, in our opinion, from an accounting viewpoint, to this profit distribution we should apply the same treatment as in the case of profit distribution for "other reserves" and, as a result, the registration in accounting should be done in the next financial year, after the General Assembly's approval of the profit distribution.

Under these circumstances, we question the usefulness of account 129 Profit distribution. In our opinion, this could be eliminated from the Chart of Accounts, according to execution regulations established by OMEF no. 3005/2009, this account having only the role to show the "reserves constituted, in agreement with the law, from the profit made in the current financial year" .

The fact that for a part of the profit's destinations the regulator allows the registration in accounting of profit distribution at 31.12.N (and, consequently, the presentation of information in the balance sheet corresponding to financial year $\mathrm{N}$ ), and for other destinations the presentation in accounting is carried out after the approval of the financial statements related to financial year $\mathrm{N}$, so in financial year $\mathrm{N}+1$, causes confusion for the one preparing the financial statements when presenting the information concerning the profit's destinations, and he feels puzzled by the term "distributable net profit", "undistributed profit", and the exemplifying model of the explanatory note Profit distribution (Note 3) does not achieve the goal for which it was created.

\section{Data related to the registration in accounting and the presentation of information on employees' profit sharing}

Another problem which arises concerning the distribution of profit is related to the part which is due for distribution as incentives representing the employees' share of the profit. In

\footnotetext{
${ }^{2}$ Commercial Companies' Law no. 31/1990, art. 183. par. 1.

${ }^{3}$ Tax Code, Art. 22, par. (1), item a).

${ }^{4}$ Besides the legal reserves, above mentioned, it is possible that, in some cases, for some entities, other reserves based on legal regulations might be constituted.
} 
the case of autonomous administration, national companies and companies with integral or majority state capital, by means of specific accounting regulations there are indications to elaborate provisions with this aim 5 .

Employees' profit sharing represents one of the destinations at which, referring to the entities above mentioned, the accounting profit is distributed after deducing the charge on profit ${ }^{6}$ (so, the net profit). Where exactly should we present, in the financial statements, such a distribution of profit? As long as the registration in accounting is done by making provisions, such values must be presented in Note 2 Provisions. On the other hand, as long as it represents a distribution from the net profit, then it should be presented in Note 3 Profit distribution. These are the reasons why, in practice, the ones preparing financial statements for some entities, being confused, present the distributed sums for employees' participation both in Note 2 and in Note 3. But, in order to present this information in Note 3, they engage in bringing back together the net profit with the value distributed at this destination. As a consequence, there is a discrepancy between the net profit for which the problem of distribution arises (Note 3) and the net profit presented in the balance sheet and in the profit and loss account.

Taking into consideration the data presented above, our opinion is that employees' profit sharing, as a destination of net profit, should be reflected in accounting as any other profit distribution, and not by constituting a provision. Even if, at first sight, we might consider that all the conditions for recognizing a provision are met, the current obligation (legal or implicit) of the enterprise has a clear covering source, it is aimed at the net profit, and should not affect the enterprise's expenses. It is as if trying to constitute provisions for dividends. Another argument to support our opinion is the necessity of ensuring constancy in presenting the information in different documents which are useful, among other things, for the analysis of economic-financial indicators. In the revenue and expense budgets, documents in which these entities engaged themselves and established their obligation to take part in the profit ${ }^{7}$, the employees' profit sharing does not appear as a part of the expenses, but represents one of the profit's destinations.

On the other hand, by the alterations of the accounting regulations applicable to the economic agents starting with 01 January 2010, they were supplemented with aspects concerning the reflection in accounting and the presentation of incentives in financial statements representing the employees' profit sharing given according to the law. Therefore, complying with accounting regulations applicable to economic agents (item 191, par. 2 and 3 ), in the financial statements of the financial year for which incentives are proposed, as representing the employees' profit sharing, their counter value is reflected under the form of a provision, the cost resulting from the employee's service, and the provision is due to be mentioned in revenues in the financial year when such incentives are given. The recognition

${ }^{5}$ See the Methodology for presenting distributed profit in accounting, on destinations stipulated in art. 1, par. (1) in GO no. 64/2001, concerning the distribution of profit in national companies, national corporations and commercial companies with integral or majority state capital, as well as in autonomous administrations, approved with amendments by Law no. 76/2001, with subsequent amendments, methodology approved by OMPF no. $128 / 2005$ concerning some accounting regulations for economic agents (item II in the Annex).

${ }^{6}$ See GO no. 64/2001, art. 1, par.1, letter. e.

${ }^{7}$ Art. 1, par. 1, letter e, in GO no. 64/2001, modified by GO no. 61/2004 approved by Law no. 414/2004, stipluates that ,national companies, national corporations and commercial companies with integral or majority state capital, as well as autonomous administrations which engaged themselves and established their obligation to take part in the profit, as a result of their employees' services for them, can offer these rights within the limit of $10 \%$ from the net profit, but not more than the equivalent of a medium monthly salary attained at the level of the economic agent, in the financial period which serves as a reference". 
of such a provision takes place only when: a) the entity has a legal or implicit obligation to make such payments as a result of previous events, and b) a clear estimation of the obligation can be made.

This provision is taken from IAS 19 contents, Employee benefits, items 17-22 regarding "profit-sharing and bonus plans", according to which "the employees receive percents from the profit only if they remain a part of the entity for a specified period". Therefore, it is considered that such an obligation results from the employees' service and, as a result, profit sharing must be recognized as an expense and not as a profit distribution. The evaluation of such implicit obligations reflects the possibility for some employees to leave the entity without receiving some percentage from the profit, and this justifies the registration of a provision. Or, in our case, it is related to the distribution of profit for a completed financial period (concluded financial year closed), and it is known if the employees remained or not in that entity over that period, and the obligations for profit sharing are certain, without the likelihood of a subsequent event to confirm them. Under the circumstances, we believe that this expense must be recognized concurrently as a debt towards the employees and not as a provision. And still, where is the contradiction? Nowhere else than in the accounting regulations. Judging all aspects, it is certain that a value cannot represent, at the same time, both a distribution of the net profit and an expense.

Although it is considered that such an obligation results from an employee's service (as stipulated in the regulations), for a unitary regulation of these aspects, it is necessary to modify the guideline concerning the "distribution of profit in national companies, national corporations and commercial companies with integral or majority state capital, as well as in autonomous administrations", in such a way that employees' profit sharing would no longer appear among the destinations of "accounting profit after deducing the charge on profit".

\section{Inconsistency in accounting regulations concerning the approval of accounting loss covering}

Accounting Law no. 82/1991, republished in 2008 (art. 19, par. 4), stipulates that "reported accounting loss is covered from the profit of the financial year and the reported one, from reserves, share premium and share capital, according to the decision of the shareholders' or associates' General Assembly. The same text, supplemented with the phrase "complying with current regulations", can also be found in Accounting Regulations approved by OMPF no. 3055/2009, item 249, par. 1. Moreover, these Accounting Regulations stipulate that "in the absence of clear legal provisions, the order of sources for covering the accounting loss is left at the choice of the general assembly of shareholders and associates, respectively, at the management board's choice". We understand that, in such a case, the management board is the one to decide the order of sources for covering the accounting loss and that the decision of the general assembly is not necessary, and this contradicts the provisions in the Accounting Law. Such a contradiction could be eliminated by replacing, in the accounting regulations mentioned above, the phrase "respectively, at the management board's choice", with the phrase "at the management board's proposal".

\section{On the necessity of an exemplifying model for explanatory notes to financial statements "Loss covering"}

In conformity with Accounting Law ${ }^{8}$, annual financial statements should be accompanied, among other things, by the proposal for profit distribution or accounting loss covering. This way, among the Accounting Regulations applicable to economic agents, the Romanian regulator elaborated a model of explanatory note, Note 3 Profit distribution, where all the

\footnotetext{
${ }^{8}$ Accounting Law no. 82/1991, republished in Official Monitor no. 454/18.06.2008, art.29.
} 
possible destinations of the profit are mentioned. So as not to leave out the case in which the result of the financial year is loss, within the same model of explanatory note its is mentioned, in a footnote sending to the title, that "in case of covering reported accounting loss, the sources for its covering shall be mentioned". We consider that, just as a model for an explanatory note was created, where the profit destinations are presented, in order to assist the ones preparing financial statements, it could be useful to have a model for an explanatory note where the sources for loss covering shall be presented. We mention that, in a study we undertook concerning the financial statements 12 economic agents, analyzing the extent to which the entities present, in explanatory notes, the supplementary information required by Accounting Regulations, we found out that none of the entities (in which the result of the financial year was loss: 3 out of 12 registered loss) presents the sources for loss covering. The reason for not presenting the information regarding the sources for loss covering could be the fact that, among the models for explanatory notes, there is no such model for this destination. Our statement is based on the following aspect: analyzing the extent to which current models for explanatory notes are used, as indicated by the Romanian regulator, we observed that all the entities in the study presented information, even though incompletely, in all the 10 explanatory notes to the financial statements. We consider that if the regulator had also elaborated an exemplifying model for an explanatory note named, for instance, Loss covering, it is certain that the entities with losses would have also respected the requirement of presenting the information on the sources for loss covering.

Another argument supporting our statement refers to the attempt made by some of those who prepare financial statements to adapt the model created by the regulator in the following manner, not a very suitable one.

\begin{tabular}{|l} 
Note 3 \\
\begin{tabular}{|l|c|}
\hline \multicolumn{2}{|c|}{ Profit distribution } \\
\hline Destination & - Ron- \\
\hline Net loss & Value \\
\hline - other reserves & 1.592 .795 \\
\hline - - egal reserves & \\
\hline - accounting loss covering & \\
\hline - profit participation & \\
\hline - dividends & 1.592 .795 \\
\hline Net loss & \\
\hline
\end{tabular}
\end{tabular}

Figure no. 1. Note 3 Profit sharing, drawn up by S.C. "Y" SA

For such an explanatory note, named, for instance, Loss covering, we consider the following presentation model to be more appropriate:

Nota 3 Loss covering
\begin{tabular}{|l|l|c|}
\hline Nr. crt. & Source for loss covering & Suma \\
\hline 1. & Loss covered by means of: & \\
\hline & - reported profit & \\
\hline & - reserves & \\
\hline & - share premium & \\
\hline & - share capital & \\
\hline 2. & Uncovered loss (reportable) & \\
\hline
\end{tabular}

Figure no. 2. Note 3 Loss covering 
If it is desired that the loss covering should be made from the profit corresponding to the future financial year (s), then, in the explanatory note, the loss will be considered an "uncovered loss" (the loss is reported for future covering).

Another clarification seems imperative. The regulator's use, in the footnote previously mentioned, of the phrase "reported accounting loss", brings to the surface the following question: does it refer to the covering of the accounting loss of the pervious years, or to the one corresponding to the financial year which has just ended? Since it concerns the notes to annual financial statements, these should make reference to the result of the current financial year, which has just ended. We consider the phrase "reported accounting loss" as inappropriate, being used for defining the loss in financial year N. The expression "current accounting loss", or the phrase in the profit and loss account, "net loss of the financial year", seems to be more suitable.

\section{Conclusion}

For the time being, there are, in the Romanian accounting regulations, a series of aspects which need clarifying or require amendments, as well as a series of problems still unresolved by the Romanian accounting regulator. Obviously, both the Romanian regulator and the ones preparing financial statements, the professional accountants, must work hard to ensure the conformity of the information presented in the financial statements with the requirements established by means of accounting regulations concerning annual financial statements, in order to obtain credible and relevant information, comparable at the European and international level.

\section{Bibliography}

1. *** The Accounting Law no. 82/1991, republished in the Official Journal of Romania no. 454/ 2008

2. *** The Commercial Companies' Law no. 31/1990, republished, with subsequent amendments

3. *** Law no. 571/2003, regarding the Tax Code, with subsequent amendments

4. *** The Order of the Public Finances Minister no. 3055/2009 for the approval of accounting regulations in compliance with European directives, published in the Official Journal of Romania no. $766 / 2009$

5. *** The Government Ordinance no. 64/2001 on profit distribution of national societies, national companies and companies with integral or majority state capital, and autonomous companies, published in the Official Journal of Romania no. 536/2001, approved with amendments by Law no. 769/2001, with subsequent amendments

6. ****** The Government Ordinance no. 61/2004, to amend paragraph (1) art. 1 of The Government Ordinance no. $64 / 2001$ on profit distribution of national societies, national companies and companies with integral or majority state capital, and autonomous companies, approved by Law no. 414/2004

7. The Order of the Public Finances Minister no. 128/2005, on certain accounting regulations applicable to economic agents, published in the Official Journal of Romania no. 153/2005

8. *** www.bvb.ro. 